\title{
Googling Insects as a New Trend in Cultural Entomology: An Italian Perspective
}

\author{
Nicola Luigi Bragazzi* \\ Department of Health Sciences (DISSAL), School of Public Health, University of Genoa, Via Antonio Pastore 1, Genoa \\ 16132, Italy
}

\begin{abstract}
Cultural entomology (CE) explores the interactions between the world of insects and mankind. Since the internet plays a major role in nowadays life, it would be of great interest to investigate the insects-related internet usage and activities. However, there are very few studies about this. For this reason, inspired by the seminal work carried out by the Japanese Takada, we decided to replicate his findings. We analyzed with Google Trends and with the wavelet power spectrum analysis (WPSA) the hit-search volumes of the most common insects. We found that the five most commonly searched insects are bees, butterflies, mosquitoes, ants and spiders which are arachnids, but are commonly believed to be insects. We found a seasonality for some insects, as confirmed by the WPSA, and with peaks related to the seasonal period in which the insects are most visible, while we could not detect any regularity or trend for other insects, which are not clearly related to any particular season. In addition, we proved that, at least in some cases, hit-search volumes were influenced by the media and that the degree of seasonal regularity as measured by the WPSA was variable. Thus, we have proven the robustness of previous finding, extending their validity also in another culture and another context. Therefore, rather than being confined to a specific culture, googling insects could be a universal behavior and attitude, even though with some cross-cultural differences. Further systematic research is needed to shed light on this topic.
\end{abstract}

Keywords: Cultural entomology (CE), google trends, insect, Italy, popularity, wavelet power spectrum analysis (WPSA).

\section{INTRODUCTION}

Cultural entomology (CE) is a multidisciplinary science situated at the intersection of entomology and the humanities, which underpins the cultural and societal implications of the complex, multifaceted reign of the insects [1-7]. CE explores how insects are thought, perceived, elaborated, used and manipulated by humans. Insects indeed have always fascinated and attracted mankind's interest, and have been portrayed in songs [8-10], movies [11], novels and poems (the so-called "poetic entomology") [12], paintings and sculptures [13], as well as have populated human dreams [14] and cuisines [15].

CE witnesses the attraction of mankind for life and its different forms of manifestation [16], a concept that the prominent biologist Edward Wilson, the founder of sociobiology [17], termed as "biophilia" (literally, love for life and for living systems) $[18,19]$. CE, moreover, represents the effort to make different disciplines converge into an integrated approach called "consilience" by Wilson [20].

Since the internet has become an important part in nowadays life, it would be meaningful to study the insects-related internet usage and activities, such as the hit-search volumes, to verify whether is possible or not to extrapolate a trend. The Internet has already proven to be a valuable medium for disseminating knowledge in the field of

*Address correspondence to this author at the Department of Health Sciences (DISSAL), School of Public Health, University of Genoa, Via Antonio Pastore 1, Genoa 16132, Italy; Tel: +39-010-353-7664; Fax: +39-010-353-7669; E-mail: nicola@genethics.ethicsoft.it entomology, both for teaching and researching purposes [21]. The specialized branch of CE specifically devoted to the systematical study of the insects-related Internet activities and usage is called "digital CE".

However, there are very few studies about this.

Inspired by the pioneering articles by Takada [22, 23], we decided to replicate his findings. Since insects are well represented in Japanese culture, he wanted to investigate the Internet activities of Japanese people, searching for particular kinds of insects. Among about 130 Coleoptera, fireflies and Dinastines or Japanese rhinoceros beetles ("Kabutomushi", in Japanese language) resulted the most preferred and searched insects. Takada speculated that these insects may be endowed with particular aesthetic properties and be related to the feeling and the pride of being Japanese ("Mono no aware"). In another article, Takada found that Japanese people tend to ambiguously perceive lampyrids ("Hotaru", in Japanese language) and that the results varied if using a writing system (hiragana or katakana) or another. In another article, Takada investigated the popularity of different scarabaeid species in Japanese society, searching in katakana script and using the Keyword Tool of Google AdWords. He confirmed his previous findings and this found that Japanese users were attracted by a small number of insects, in particular those exhibiting peculiar and distinctive morphological and ecological traits, associated with human survival and habitat, or highly common in Japan. Kabuto-mushi Trypoxylus dichotomus resulted once again the most searched insect. Takada concluded suggesting that, on the basis of this find- 
ing, Japanese rhinoceros beetles could be exploited as a flagship species for conservation campaigns.

Another scholar that investigated this topic is Yuma [24], who confirmed the interest of Japanese culture towards insects.

$\mathrm{CE}$ can indeed have many implications, both scientific and societal. It reflects the growing importance of the socalled "citizen science" [25] (also termed as "crowd science" [26], "crowd-sourced science" [27], "civic science" [28], "networked science" [29], "small artisan science" [30] or "shared science" [31]) in which the barrier between scholars and lay people becomes blurred and citizen empowerment enables amateur or nonprofessional scientists to carry out scientific research, in whole or at least in part, being actively engaged in scientific activities (data collections, use of technologies, etc.). Crowd-sourcing, crowd-funding and public education play a major role. It is noteworthy that citizen science developed from ornithology and biological sciences $[32,33]$.

\section{EXPERIMENTAL SECTION}

We used Google Trends searching for some of the most common insects. Google Trends, an online tracking system of Internet hit-search volumes that recently merged with its sister project Google Insights for Search (Google Inc.), was searched for the years 2004 to 2013 (as data before 2004 were not available) [34].

Google Trends has been extensively used for predicting infectious epidemics and outbreaks [35], studying patients attitudes towards their diseases or their compliance to treatment [36], in neurology [37-40], in psychiatry [40,41], in oncology $[42,43]$, as well as in nephrology and urology [4547], ophthalmology [48,49], gynecology [50], otolaryngology [51], cardiovascular [52,53] and bariatric surgery [52]. However, Google Trends has been used not only in the medical field within the framework of P6 medicine (a model of patient-centered medicine, in which the patient actively seeks for health-related information on the Internet) $[54,55]$, but also for biological [56], economic and financial [57,58] disciplines.

Flux volumes of each hit-search data were inspected looking for regularity and analyzed also using the wavelet power spectrum analysis (WPSA), a mathematical technique that enables to establish a cyclic trend, by decomposing a time series into time versus frequency space. WPSA was performed with the application developed by Torrence and Pompo $[59,60]$. WPSA is usually used in geophysics, meteorology and biophysics, and has been recently applied also to time series derived from Google Trends [37] and to real epidemiological data [61].

\section{RESULTS AND DISCUSSION}

With Google Trends we analyzed the hit-search volumes of the most common insects, we inspected the curves for regularity and we assessed quantitatively the trend with the WPSA. Generally speaking, the search for "insects" exhibits a regular pattern over the time (Fig. 1).

The five most searched insects are: bees, mosquitoes, butterflies, ants and spiders which are arachnids, but are commonly believed to be insects (Fig. 2).

For some insects, we managed to find a cyclic regularity (Fig. 3), with peaks clearly related with the season in which these insects are most visible. WPSA confirmed this regularity (Fig. 4).

We could not detect any regular trend instead for other insects, like gnat, or moth, which are not prominently correlated with a specific season.

We succeeded in replicating the Takada's findings. Moreover, we provide two novel evidences. The first is that the degree of seasonal regularity varies among the searched words, being higher for "mosquito" (Fig. 3a). The second evidence is that interests in searching and looking for insects may be fostered by the new media. As can be noticed in Fig. (3d), hit-search volume for "sago palm weevil"
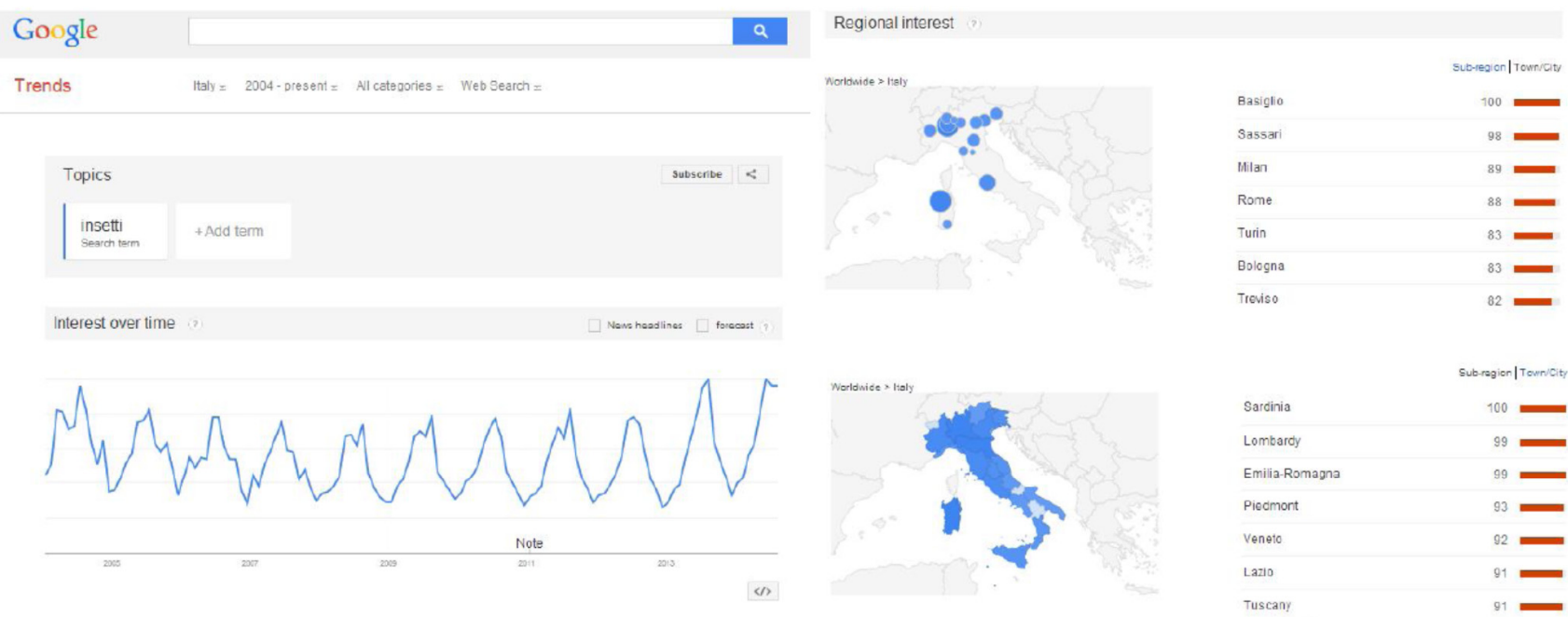

Fig. (1). Hit-search volumes of the word "insects", exhibiting a regular cyclic trend over the time and for which it is possible to detect a regular searching pattern in Italy. 


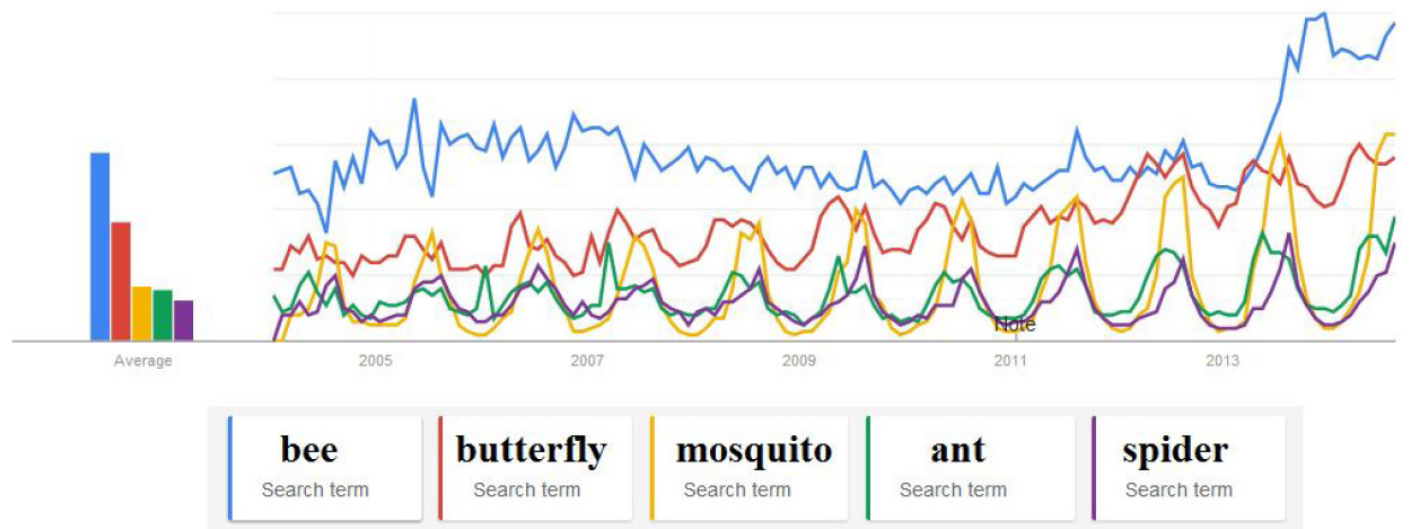

Fig. (2). Hit-search volumes of the five most searched insects in Italy.

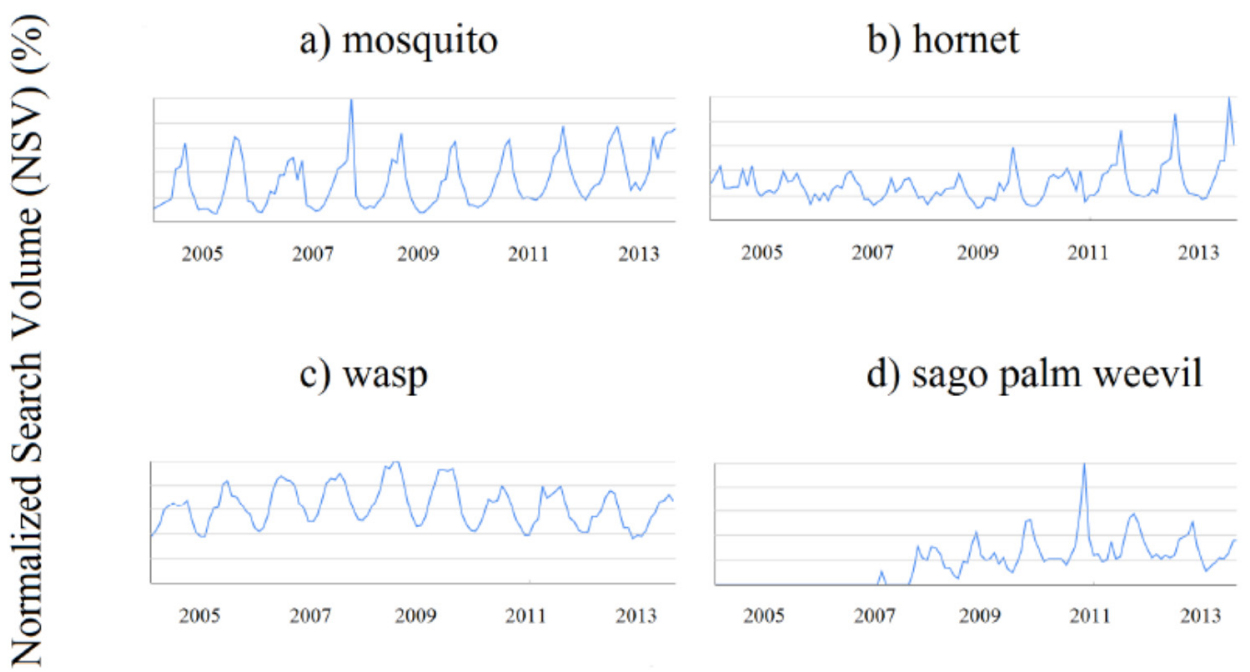

Fig. (3). Hit-search volumes of some common insects for which it is possible to detect a regular pattern and cyclic seasonal trend.
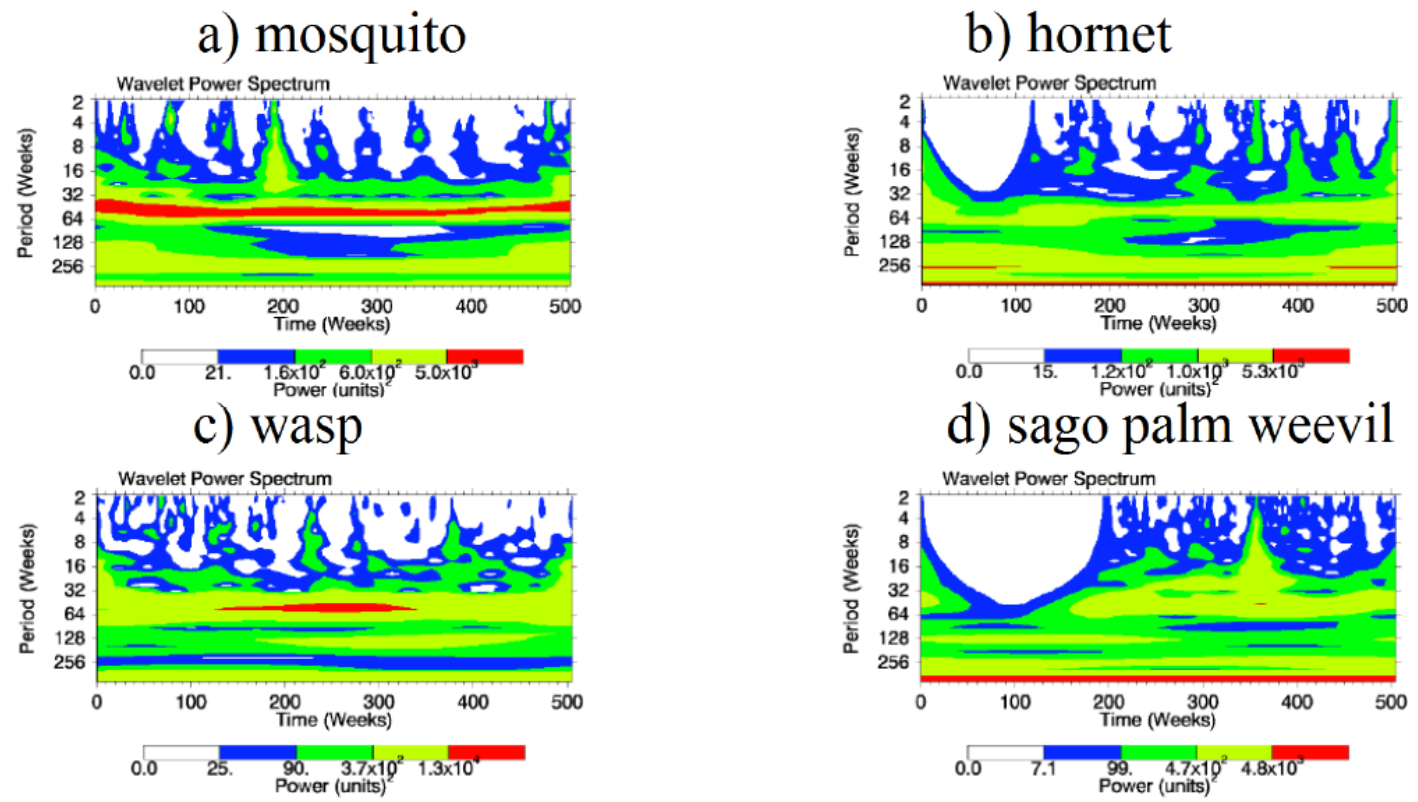

Fig. (4). WPSA of the same insects searched in Figure 3, showing the degree of regularity in the seasonal cyclic pattern. 
("punteruolo rosso delle palme", in Italian) before 2007 was negligible but increased afterward thanks to the increasing attention and the warnings of the television and the Internet of potential dangerous impact of these insects on agriculture.

\section{CONCLUSION}

Despite its limitations, this article shows that Google Trends can be exploited as a useful tool to investigate the hit-search volumes of insects. Google Trends, thus, could be extremely useful for $\mathrm{CE}$, showing the pattern and the trends of search.

WPSA can complement the manual inspection of the Google Trends-generated curves, assessing in a quantitative rigorous way the regularity.

Inspired by the seminal work carried out by the Japanese Takada, we decided to replicate his findings. We analyzed with Google Trends and with WPSA the hit-search volumes of the most common insects. We identified the five most commonly searched insects: they exhibit particular aesthetic properties (such as the butterflies) or are eusocial insects (such as the bees and the ants) or can represent threat and danger for individuals (such as spiders and mosquitoes). We found a seasonality for some of them, as confirmed by the WPSA, and with peaks related to the seasonal period in which the insects are most visible, while we could not detect any regularity or trend for other insects, which are not clearly related to any particular season. In addition, we proved that at least in some cases hit-search volumes were influenced by the media and that the degree of seasonal regularity as measured by the WPSA was variable. Thus, we have proven the robustness of previous finding, extending their validity also in another culture and another context. Therefore, rather than being confined to a specific culture, googling insects could be a universal behavior and attitude, even though with some cross-cultural differences. Further systematic research is needed to shed light on this topic.

\section{CONFLICT OF INTEREST}

The authors confirm that this article content has no conflict of interest.

\section{ACKNOWLEDGEMENTS}

The author wishes to thank anonymous referees for helpful suggestions and comments that have improved the manuscript.

\section{REFERENCES}

[1] Hogue CL. Cultural entomology. Annu Rev Entomol 1987; 2:18199.

[2] Hogue LC. Commentaries in cultural entomology: Definition of cultural entomology. Entomol News 1980; 91:33-6.

[3] Mitsuhashi J. Cultural entomology. Heredity 2000; 54:14-5.

[4] Takada K. Cultural coleopterology: an outline of cultural entomology of coleopteran insects. Coleopt News 2010; 170:13-8.

[5] Hoshina H, Takada K. Cultural Coleopterology in Modern Japan: The Rhinoceros Beetle in Akihabara. Am Entomol 2012; 58(4): 202-7.

[6] Leclercq J. De l'entomologie culturelle a l'ethnoentomologie. Ann Soc Entomol France 1999; 35(Suppl):556-9.

[7] Wennemann L. Kulturelle entomologie II. Gesunde Pflanz 2004; 56(2): 61-6.
[8] Coelho JR. Noninsect Arthropods in Popular Music. Insects 2011; 2(2): 253-63.

[9] Coelho JR. Insects in rock and roll music. Am Entomol 2000; 46: 186-200.

[10] Coelho JR. Insects in rock and roll cover art. Am Entomol 2004; 50: $142-51$.

[11] Leskosky JR, Berenbaum MR. Insects in animated films. Not all "bugs" are bunnies. Bull ESA 1988; 35:55-63.

[12] Dunn RR. Poetic entomology: Insects in Japanese haiku. Am Entomol 2000; 46: 70-2.

[13] Capinera JL. Insects in Art and Religion: The American Southwest. Am Entomol 1993; 39(4): 221-30.

[14] Klein BA. The curious connection between insects and dreams. Insects 2012; 3:1-17.

[15] Morris B. Insects as food among hunter-gatherers. Anthrop Today 2008; 24(1): 6-8

[16] Wilson EO. The Insect Societies US: Harvard University Press 1971; ISBN 0-674-45490-1

[17] Wilson EO. Biophilia. Cambridge: Harvard University Press1984.

[18] Kellert SR, Wilson EO. The Biophilia Hypothesis. Shearwater Books 1993.

[19] Wilson EO. Consilience: The Unity of Knowledge US: Vintage Books 1998.

[20] Zenger JT, Walker TJ. Impact of the internet on entomology teaching and research. Ann Rev Entomol 2000; 45: 747-67.

[21] Takada K. Popularity of Different Lampyrid Species in Japanese Culture as Measured by Google Search Volume. Insects 2011; 2: $336-42$.

[22] Takada K. Japanese Interest in "Hotaru" (Fireflies) and "KabutoMushi" (Japanese Rhinoceros Beetles) corresponds with seasonality in visible abundance. Insects 2012; 3: 424-31.

[23] Takada K. Exploitation of flagship species of scarabaeid beetles with application of analyzed results on cultural entomology. Appl Ecol Environ Sci 2013; 1(1): 1-6.

[24] Yuma M. How to Japanese See Dragonflies. Kyoto: Kyoto University Press 2004; pp. 377-407. (In Japanese).

[25] Conrad CC, Hilchey KG. A review of citizen science and community-based environmental monitoring: issues and opportunities. Environ Monit Assess 2011; 176(1-4): 273-91.

[26] Luciano JS, Cumming GP, Wilkinson MD, Kahana E. The emergent discipline of health web science. J Med Internet Res 2013; 15(8): e166.

[27] Block KL, Rolshausen PE, Cantu D. In search of solutions to grapevine trunk diseases through "crowd-sourced" science. Front Plant Sci 2013; 4: 394.

[28] Harrison CE. Citizens and scientists: toward a gendered history of scientific practice in post-revolutionary France. Gend Hist 2001; 13(3): 444-80.

[29] Khoo SM. Re-interpreting the citizen consumer: alternative consumer activism and the rights to health and development. Soc Sci Med 2012; 74(1): 14-9.

[30] Özdemir V, Badr KF, Dove ES, et al. Crowd-funded micro-grants for genomics and "big data": an actionable idea connecting small (artisan) science, infrastructure science, and citizen philanthropy. OMICS 2013; 17(4): 161-72.

[31] Goss C, Renzi C. Patient and citizen participation in health care decisions in Italy. Z Arztl Fortbild Qual 2007; 101(4): 236-40.

[32] Kremen C, Ullman KS, Thorp RW. Evaluating the quality of citizen-scientist data on pollinator communities. Conserv Biol 2011; 25(3): 607-17.

[33] Matteson KC, Taron DJ, Minor ES. Assessing citizen contributions to butterfly monitoring in two large cities. Conserv Biol 2012; 26(3): 557-64.

[34] Available at: http://www.google.it/trends/?hl=it

[35] Dukic V, Lopes HF, Polson NG. Tracking epidemics with Google Flu trends data and a state-space SEIR model. J Am Stat Assoc 2012; 107(500): 1410-26.

[36] Schuster NM, Rogers MA, McMahon LF Jr. Using search engine query data to track pharmaceutical utilization: a study of statins. Am J Manag Care 2010; 16(8): e215-9.

[37] Bragazzi NL. Infodemiology and infoveillance of multiple sclerosis in Italy. Mult Scler Int 2013; 2013: 924029.

[38] Ingram DG, Matthews CK, Plante DT. Seasonal trends in sleepdisordered breathing: evidence from Internet search engine query data. Sleep Breath 2014. [Epub ahead of print] 
[39] Barnes CM, Gunia BC, Wagner DT. Sleep and moral awareness. J Sleep Res 2014. [Epub ahead of print]

[40] Brigo F, Igwe SC, Ausserer H, et al. Why do people Google epilepsy: an infodemiological study of online behavior for epilepsyrelated search terms. Epilepsy Behav 2014; 31: 67-70.

[41] Bragazzi NL. A Google Trends-based approach for monitoring NSSI. Psychol Res Behav Manag 2013; 7:1-8.

[42] Yang AC, Huang NE, Peng CK, Tsai SJ. Do seasons have an influence on the incidence of depression? the use of an internet search engine query data as a proxy of human affect. PLoS One 2010; 5(10): e13728.

[43] Fazeli Dehkordy S, Carlos RC, Hall KS, Dalton VK. Novel data sources for women's health research: mapping breast screening online information seeking through google trends. Acad Radiol 2014; 21(9): 1172-6.

[44] Noar SM, Ribisl KM, Althouse BM, Willoughby JF, Ayers JW. Using digital surveillance to examine the impact of public figure pancreatic cancer announcements on media and search query outcomes. J Natl Cancer Inst Monogr 2013; 2013(47): 188-94.

[45] Breyer BN, Sen S, Aaronson DS, Stoller ML, Erickson BA, Eisenberg ML. Use of Google Insights for Search to track seasonal and geographic kidney stone incidence in the United States. Urology 2011; 78(2): 267-71.

[46] Davis NF, Breslin N, Creagh T. Using google trends to assess global interest in 'Dysport ${ }^{\circledR 1}$ for the treatment of overactive bladder. Urology 2013; 82(5): 1189.

[47] Rossignol L, Pelat C, Lambert B, Flahault A, Chartier-Kastler E, Hanslik T. A method to assess seasonality of urinary tract infections based on medication sales and google trends. PLoS One 2013; 8(10): e 76020

[48] Leffler CT, Davenport B, Chan D. Frequency and seasonal variation of ophthalmology-related internet searches. Can J Ophthalmol 2010; 45(3): 274-9.
[49] Stein JD, Childers DM, Nan B, Mian SI. Gauging interest of the general public in laser-assisted in situ keratomileusis eye surgery. Cornea 2013; 32(7): 1015-8.

[50] Brito LG, Ferriani RA, Candido-Dos-Reis FJ, Nogueira AA. Using a search-volume tool (Google Trends) to assess global interest for uterine fibroids. Arch Gynecol Obstet 2014; 289(6): 1163-4.

[51] Braun T, Harréus U. Medical nowcasting using Google Trends: application in otolaryngology. Eur Arch Otorhinolaryngol 2013; 270(7): 2157-60.

[52] El-Sheikha J. Global search demand for varicose vein information on the internet. Phlebology 2014. [Epub ahead of print]

[53] Linkov F, Bovbjerg DH, Freese KE, Ramanathan R, Eid GM, Gourash W. Bariatric surgery interest around the world: what Google Trends can teach us. Surg Obes Relat Dis 2014; 10(3): 533-8.

[54] Bragazzi NL. Children, adolescents, and young adults participatory medicine: involving them in the health care process as a strategy for facing the infertility issue. Am J Bioeth 2013; 13(3): 43-4.

[55] Bragazzi NL. From P0 to P6 medicine, a model of highly participatory, narrative, interactive, and "augmented" medicine: some considerations on Salvatore Iaconesi's clinical story. Patient Prefer Adherence 2013; 7: 353-9.

[56] Proulx R, Massicotte P, Pépino M. Googling trends in conservation biology. Conserv Biol 2014; 28(1): 44-51.

[57] Kristoufek L. BitCoin meets Google Trends and Wikipedia: quantifying the relationship between phenomena of the Internet era. Sci Rep 2013; 3: 3415

[58] Preis T, Moat HS, Stanley EH. Quantifying trading behavior in financial markets using google trends. Sci Rep 2013; 3: 1684.

[59] Available at: http://paos.colorado.edu/research/wavelets/

[60] Torrence C, Compo GP. A practical guide to wavelet analysis. Bull Am Meteorol Soc 1998; 79(1): 61-78.

[61] Grenfell BT, Bjørnstad ON, Kappey J. Travelling waves and spatial hierarchies in measles epidemics. Nature 2001; 414(6865): 716-23.

Received: May 09, 2014

Revised: August 30,2014

Accepted: September 01, 2014

(C) Nicola Luigi Bragazzi; Licensee Bentham Open

This is an open access article licensed under the terms of the Creative Commons Attribution Non-Commercial License (http://creativecommons.org/licenses/by-nc/3.0/) which permits unrestricted, non-commercial use, distribution and reproduction in any medium, provided the work is properly cited. 